\title{
Research on Sedimentary Microfacies of P II Oil Layer Group in S Oilfield
}

\author{
Xiaoyu Yang ${ }^{1, a}$, Ning Gan ${ }^{2, b}$,Hao Zhang ${ }^{3, \mathrm{c}}$ and Liang Zhang ${ }^{4, \mathrm{~d}}$ \\ ${ }^{1}$ College of Earth Science, Northeast Petroleum University, Daqing, Heilongjiang, China \\ ${ }^{2}$ Reservoirs Evaluation Center, China Petroleum Logging CO. LTD.,Xi'an , China \\ ${ }^{3}$ No.6 Oil Production Company, Daqing Oilfield Limited Company, China \\ ${ }^{4}$ College of Earth Science, Northeast Petroleum University, Daqing, Heilongjiang, China \\ a937208900@qq.com, b1239131045@qq.com, cwanlianggongzi@sina.com,d937208900@qq.com
}

Keywords: P II oilOil Layer Group; Sedimentary Microfacies; S Oilfield; Eletrofacies Model

\begin{abstract}
Based on the static and dynamic data of hydrocarbon reservoir achieved from each stage, guided by high-resolution sequence stratigraphy and delicate fluviatile sedimentology, this paper completed the research on sedimentary microfacies of P II oil layer group within the research scope, which belongs to the leading edge of river-delta depositional system. Researchers successfully identified fThe types of sedimentary microfacies, including underwater distributary channel, sheet sand, mouth bar and inter-distributary mud. Eletrofacies model was established on the conclusive feature of each sedimentary microfacies. Then researchers accomplished the stratigraphic division and correlation and sedimentary facies analysis of 12 sedimentary units, which help conclude the sedimentary evolution of target stratigraphic position. The final results will surely provide a reliable theoretical basis for oil production.
\end{abstract}

\section{Introduction}

After years of waterflood development, the research area has reached the latter stage of high water cut, resulting in extremely complex distribution pattern of remaining oil in various types of reservoirs. In order to tap the further potential of remaining oil and enhance hydrocarbon recovery, based on the static and dynamic data of hydrocarbon reservoir achieved from each stage, guided by high-resolution sequence stratigraphy and delicate fluviatile sedimentology, this paper completed the sedimentary facies analysis of 12 sedimentary units in P II oil layer group within the research area. The summary of sedimentary evolution in target stratigraphic position will eventually provide a reliable theoretical basis for the oil production.

\section{Geology}

S Oilfield is located at S structure in the south of Daqing placanticline - - the central downwarping region of Songliao basin. The research area belongs to anticline sandstone reservoir. In the early Cretaceous Period, G, P and S 3 sets of oli reservoirs were deposited upwards during the large-scale water withdrawal - water intake process, corresponding Q-Y-N stratum. The target reservoir of this essay,is P II oil layer group of P oil reservoir in the bottom part of Y stratum. Sandstone and 
argillaceous sandstone are the major lithology of reservoirs and bedding is well developed within the research area, except the numerous vontinental fossils.

\section{Types of Sedimentary Microfacies}

On the basis of accurate core observation and description, along with the sedimentary background and reservoir characteristics, researchers believed that the type of subfacies within research area is delta fringe deposit, according to the cross-sectional structure of rock and sedimentary evolution. The identified types of sedimentary microfacies are underwater distributary channel, sheet sand, mouth bar, inter-distributary mud and the characteristics of each microfacies are as follows:

Underwater distributary channel is the extension part of distributary channel beneath water, which has undermining, bottom stranded deposition, vertical channel sequence and other kinds of typical channel characteristics. The lithological combination of medium sandstone, packsand and siltstone usually presents apparent positive cycle, but the thickness is less than distributary channel. Parallel bedding and small-scale cross bedding are quite developed. Except the distributary channel, the unique lake-energy bedding is well developed in the underwater distributary channels due to the association of inter-distributary mud.

Sheet sand is the wide-rage thin sandbody formed with the dual reformation of channel and lake energy after distributary channel flow into the water. Its general lithology is shale with gray-green, green-gray parallel, horizontal wavy, massive bedding, and silty mudstone, argillaceous siltstone is also included sometimes. Researchers can easily find sheet sand between two sets of mudstone.

Mouth bar is located at the mouth of underwater distributary channel. It is usually consist of gray, gray-green siltstone clipped with argillaceous siltstone. Groove-like or wave ripple cross-bedding and intermittent wave bedding are quite developed while muddy strip and deformation structure is only visible sometimes. And the inverted prosody feature (granularity coarsening upward) of mouth bar can help us distinguish it from other kinds of microfacies.

Inter-distributary mud is the deposition between underwater distributary channel with little thin sand layer. Its main lithology is thick purple, varied, gray-green mudstone and massive mud bedding, calcium tablets, plant roots and wormhole are thus easily be formed while animal fossils are rare.

\section{The Establishment of Eletrofacies Model}

Logging traces can well respond to the relationship between the three types of characteristics(lithology, physical property and oiliness), shale content, lithological interface, contact relationship between top and bottle interface, cyclicity and other characteristics of reservoirs. So the logging curve combination of spontaneous potential (SP), micronormal (RMN) and (RMG) with obvious respond, considering the amplitude, shape, smoothness and cycle amplitude of logging curve, was choose to establish the eletrofacies model of target reserrvoirs. The logging element characteristics of each microfacies are thus concluded as researchers can see in Fig. 1:

Underwater distributary channel:SP curve is usually presents as box-shape or aliasing bell-shape with abrupt contact at the bottom while the contact at top is abrupt or gradually.And the RMN and RMG curve is bell-shaped, aliasing bell-shaped or box-shaped with abrupt contact at the bottom and gradual contact at the top.So the amplitude difference of RMN and RMG at bottom is larger than at top. 
Sheet sand: SP curve is single-finger or very flat funnel-shaped when RMN and RMG curve are multi-finger or very flat funnel-shaped or bell-shaped with medium-low amplitude difference. Unlike other kinds of microfacies, sheet sand is extremely thin-thin layers, which can be easily identified.

Mouth bar: SP curve shows obvious negative abnormality with anti-cycle characteristics when RMG and RMN curve shows high amplitude, media-high amplitude difference and funnel or aliasing funnelshape. The contact relationship at the bottom is gradually changed while sudden change could be seen at the top.

Inter-distributary mud: The abnormality amplitude of SP curve decreases and the amplitude difference between RMG and RMN is quite small or next to never. All the curves shows the lowest amplitude and straight shape with few dactylic waves. And it is generally thick layer.

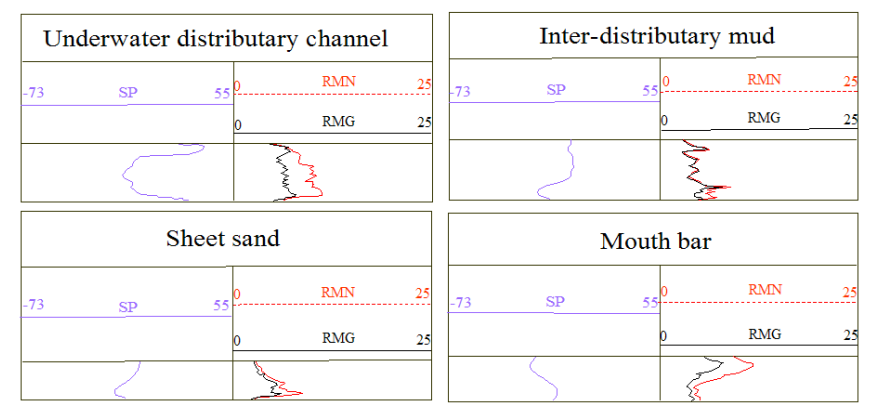

Fig. 1 Logging element characteristics of each microfacies

\section{The Flat Distributional Characteristics of Sedimentary Microfacies}

After obtaining the lithology, logging curve and other aspects of recognization about research area,we researchers believe that P II oil group has the sedimentary characteristis of delta fringe subfacies.So based on the establishment of eletrofacies model, using combination of advantage facies and the prediction principle of single-sand flat distribution, this paper carried out the logging microfacies identification of each sedimentary units, which obtain us the flat distribution characteristics of sedimentary microfacies of P II oil group. The 12 sedimentary units of P II oil group are individually belong to nearshore, middleshore or infralittoral deposit of delta fringe subfacies. The sedimentary deposit characteristics of each type, cited as example, are as following:

The nearshore deposit of delta fringe sedimentary system lies quite near to the boundary line between distributary plain and interior front of delta. As the flat terrain area where the distributary channel has just entered lake and the water is very scattered, by the strong influence of lake, the nearshore deposit of delta fringe has taken the strongest affection of the river in delta fringe area. There are 5 sedimentary units belong to this kind of deposit. Take P II 6 - the small-scale to mid-scale underwater distributary channel deposit in the nearshore of interior delta front as example: The mainly sedimentary microfacies types are small-scale and mid-scale underwater distributary channel, mouth bar, sheet sand and inter-distributary mud. There are 6 mid-scale and 1 small-scale underwater distributary channel. The spread direction of underwater distributary channels is mostly along the sedimentary provenance direction - north to south.Compared with delta distributary plain, the channel scale of this kind of sedimentary units is relatively small and the sand body is poorly developed. Inter-distributary mud is the most widespread micorfacies while mouth bar and sheet sand covered the areas between underwater distributary channel and inter-distributary mud. Generally speaking, the reservoir is not well developed, causing the relatively poor oil in this area. 
The middleshore deposit of delta interier fringe sedimentary system is located at the further extends position from estuary area of underwater distributary channel. It belongs to river-controlled, shallow delta sedimentary system with distant source and long flow. Under the dual affection of relatively weak gluvial energy and strong lake energy, the distribution style of river-controlled sheet sand could be easily seen. There are 6 sedimentary units belong to this kind of deposit.Take P II 3a sedimentary unit as example: The mainly sedimentary microfacies types are small-scale and mid-scale underwater distributary channel, mouth bar, sheet sand and inter-distributary mud. There are 6 mid-scale and two small-scale banded underwater distributary channel. The spread direction of underwater distributary channels is the same as nearshore deposit. The width of channel and the sickness of sand are smaller than nearshaore deposit. Mouth bar and sheet sand cover the most area on both sides of channels due to the strong influence of lake energy. Inter-distributary mud could only be seen in a few area. As a result, reservoir is well developed.

The infralittoral deposit of delta interior fringe sedimentary system is located at the disappear zone of underwater distributary channel. Its sedimentary characteristics were mainly affected by lake energy. Take the only sedimentary unit of this type - P II 10a as example: The mainly sedimentary microfacies types are small-scale underwater distributary channels, mouth bar, sheet sand and inter-distributary mud. There are only two banded and few iump-shape underwater distributary channels scattered in the whole research area, which is clearly narrower than other sedimentary types or even vanished. The spread direction of underwater distributary channels is mostly along the sedimentary provenance direction. Sheet sand and mouth bar is extremely developed while inter-distributary mud could only be seen in a few north areas. As a result, reservoir is not well developed.

Generally speaking, the basal lever of P II oil group experienced two times of water transgressive and withdrawal progress,a slow one after a rapid one. The overall performance is middleshore deposit - infralittoral deposit - nearshore deposit - middle shore deposit - nearshore deposit middle shore deposit of delta interior fringe.

\section{Summary}

The sedimentary system of research area belongs to delta interier fringe. The mainly identified types of sedimentary microfacies are underwater distributary channel, sheet sand, mouth bar and inter-distributary mud of delta fringe subfacies.

Based on the precise core description, researchers obtained the flat distribution characteristics of 12 sedimentary units in P II oil group: 5 nearshore, 6 middleshore and 1 infralittoral deposit of delta fringe subfacies. And P II oil group experienced two times of water transgressive and withdrawal progress, a slow one after a rapid one.

\section{References}

[1] Miall A D. Architecture Eelement Analysis: a New Method of Faciesanalysis Applied to Fluvial Deposits. Earth Science Review. 1985, 22(4): 261-308.

[2] Wen Huijian,etc.Rethicking of Sedimentary Facies of SI Reservoir in the North Part of Saertu Oilfield in Daqing, J.Technology Review,2012 30(7):39-43. 
[3] Wen Huijian. Study of Sedimentary Facies of Gaotaizi Reservoir in the North Part of Daqing Placantieline, J. Daqing Petroleum Institute, 2002.

[4] Zhao Hanqing. A Sedimentary Scheme and Heterogeneous Character for a Large Scale Fluvial Delta Sand in the North of Songliao Basin. Daqing: Exploration and Development Academy,Daqing Petroleum Administrative Bureau,1992,9:1-45.

[5] Zhao Hanqing, etc. Methods for Detailed Description of Large Fluvial-delta Depositional Reservoir, D. Acta Petroleum Sinica, 2000 21(4):109-113.

[6] Shi Shangming, Fan Zili,Fu Hongjun, The Sedimentary Microfacies of HIII Oil Group in Shuanghe Oilfield, J.Petrileum Geology and Oilfield Development in Daqing,2008,27(5):34-37.

[7] Cornel Olariu,Janok P Bhattacharya,Teeminal Distributary Channels and Delta Front Architecture of River-dominated Delta Systems. Journal of Sedimentary Research,76:212-233.

[8] Miall A D, Rservoir Heterogeneitiea in Fluvial Sandstone: Lessons from Outcrop Studies, J. 72(6): 682-697.

[9]CartwrightJ, Huuse M.3D Seismic Technology: the Geological Hubble [J]. Basin Research,2005 , (17):1-20.

[10]Pickering K T, et al. Deep Marine Environments, Clastic Sedimentary and Tectonic, 1989. Unwin-Hyman. 